\title{
Rice + Fish Farming in Homesteads: Sustainable Natural-Resource Management for Subsistence in Arunachal Pradesh, India
}

\author{
Sumpam Tangjang ${ }^{1,2}$ and P. K. Ramachandran Nair ${ }^{1}$ \\ 1. School of Forest Resources and Conservation, University of Florida, Gainesville 32611, Florida \\ 2. Department of Botany, Rajiv Gandhi University, Doimukh 791112, Arunachal Pradesh, India
}

Received: November 09, 2015 / Accepted: November 11, 2015 / Published: December 10, 2015

\begin{abstract}
Understanding the attributes of traditional, location-specific land-use systems will provide insights for improvement of such systems and design of new ones for wider applicability. The integrated rice + fish system developed by the Apatani tribe of Ziro valley, Arunachal Pradesh, Northeastern India is such a unique system. Faced with shortages of their staple food items (rice and fish), these subsistence farmers developed this ingenious system — in preference to the wide-spread shifting cultivation in the region - by capitalizing on the good water supply (from rainfall supplemented by natural flow from hills surrounding the valley). Two rice crops are grown annually and fish is reared in paddy fields during the main rainy season. Crop residues and animal wastes are the sources of nutrients to crops, chemical fertilizers and insecticides are not used. Over the years, rice yield has been stable at about 3,700 $\mathrm{kg} \cdot \mathrm{ha}^{-1} \cdot \mathrm{year}^{-1}$. Recently, UNESCO has tentatively added the valley as a "world heritage site" recognizing its "extremely high productivity" and "unique" ecological preservation. The resilience and the sustainability of the system could be attributed to efficient nutrient cycling and nutrient input through water seeping in from surrounding hills, which have not been, but deserve to be, quantified.
\end{abstract}

Key words: Apatani tribe, ecosystem conservation, sustainability.

\section{Introduction}

The traditionally managed agroecosystems around the world represent a picture of "unity in diversity". They possess some common traits and similarities among themselves. At the same time, they are also extremely complex and diverse with tremendous variation in structure and function. It is well understood that these inherent variations among such systems reflect the characteristic traits of the diverse socioeconomic and ecological conditions under which the systems have developed and been managed over the millennia [1-3]. Faced with the increasingly recognized adverse impact of chemical agriculture on the ecology and environment, the concept of

Corresponding author: Sumpam Tangjang, Ph.D., main research fields: agroforestry and biodiversity conservation. ecology-based production system has been gaining importance in the recent past. New approaches and technologies involving application of agroecological science blended with indigenous knowledge systems led by farmers, NGOs and academic institutions have shown to enhance food security, while conserving biodiversity, and soil and water resources throughout hundreds of rural communities in several regions [4]. The science of agroecology - the application of ecological concepts and principles to the design and management of sustainable agricultural ecosystems - provides a framework to assess the complexity of such agroecosystems [5]. Understanding the structural, functional, and socioecological attributes of such traditional systems that have been practiced for long in different parts of the world will provide valuable insights for the development of such systems 
as well as design of new ones for a variety of conditions.

Agriculture is the mainstay of livelihood in Arunachal Pradesh and about 80 percent of the rural populations depend largely on indigenous farming systems such as shifting cultivation, rotational fallow, wet-rice cultivation, and traditional homegarden agroforestry systems. For centuries, the agriculture in Arunachal Pradesh has been built upon the local resources of land, water, and other resources relying on local varieties and indigenous knowledge. These time-tested practices have fostered biologically diverse smallholder farms with a robustness and a built-in resilience and ability to adjust to rapidly changing climates, pests and diseases [6]. The rice + fish farming system in Ziro valley of Arunachal Pradesh, India, as part of an integrated ecosystem in line with the local cultural, environmental and economic conditions, is composed of complementary sub-agricultural ecosystems and play an important role in provisioning services, including genetic diversity for future agricultural use, soil retention, regulation of soil fertility and nutrient cycling. The ecological, social, and economic values of different forms of traditional land-use practices followed by various ethnic communities and indigenous groups in different parts of the world have seldom been studied and understood. This paper highlights the traditional expertise in the management of a unique rice + fish farming and analyses the ecological principles underlying the success of this traditional system in fragile eastern Himalaya region in particular and other mountainous regions in general.

\section{Methods}

\subsection{Studied Area}

Arunachal Pradesh, popularly called the "Orchid State of India" or the "Paradise of the Botanists", is located at $26^{\circ} 28^{\prime}-29^{\circ} 30^{\prime} \mathrm{N}$ and $91^{\circ} 30^{\prime}-97^{\circ} 30^{\prime} \mathrm{E}$. Geographically, it is the largest (approximately $84,000 \mathrm{~km}^{2}$ ) among the north-east Indian states commonly known as the "Eight Sister States". The state, one of the remotest and poorest in India due to its predominantly challenging rugged topography, inhospitable mountainous terrain, incessant rains and harsh climatic conditions is sparsely populated (total population: about 1.38 million, population density: 17 persons per $\mathrm{km}^{2}$ - compared with 382 persons per $\mathrm{km}^{2}$ for India as a whole) among the Indian states. The state's inhabitants are predominantly $(77 \%)$ rural and represent many of India's so-called scheduled tribes. Twenty-six major tribes and myriads of colorful sub-tribes have been recognized in the state. The state is bordered by Bhutan to the west, Myanmar (Burma) to the east, the Tibetan region of the Peoples Republic of China in the north and the Indian states of Assam and Nagaland to the south.

The study was undertaken in Ziro valley (Fig. 1), the district headquarter of lower Subansiri $\left(26^{\circ} 55^{\prime}-28^{\circ} 21^{\prime} \mathrm{N}\right.$ and $\left.92^{\circ} 40^{\prime}-94^{\circ} 21^{\prime} \mathrm{E}\right)$ and home to the ethnic Apatani, one of the major tribes of Arunachal Pradesh. The Apatani tribe is said to have migrated to the present location from the Talle valley in the southeastern region of lower Subansiri district [7] which is about $30 \mathrm{~km}$ away from Ziro valley for some time before shifting the base to the study site. Geographically, the study site with a total area of about $1,000 \mathrm{~km}^{2}$ is a bowl-shaped and is surrounded by high hills interspersed with unique and a highly developed ingenious integrated rice + fish farming (locally called Aji-Ngyii) and bamboo + pine homegarden agroforestry systems. It has 35 villages, with a total population of about 42,000 and a population density of 24 people per $\mathrm{km}^{2}$ [8]. The majority of the rural Apatani economy is largely based primarily through a mixture of agricultural activities centered on crops [9], fishery and homegarden agroforestry resources. They elegantly integrate animal husbandry comprising of mithun (Bos frontalis Lam.), cattle, swine and poultry in this traditional farming system. 


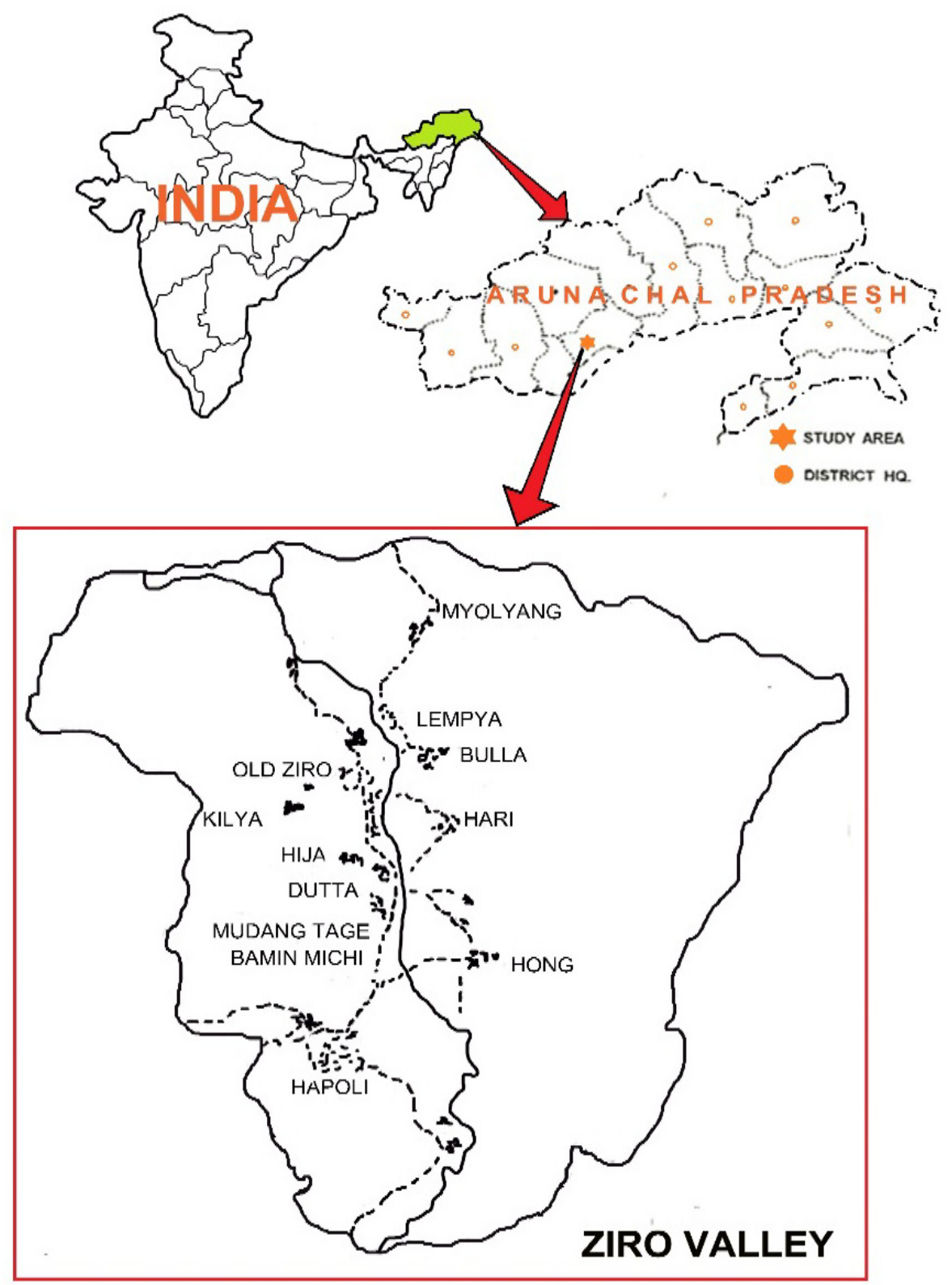

Fig. 1 Map showing the studied area (Ziro valley or Apatani valley) of Arunachal Pradesh, India.

The Ziro valley is bifurcated by the Kele river and lies between the river valleys of Kamla and Khru on the north and Palin on the south. All these rivers eventually drain into the Subansiri river, a tributary of the Brahmaputra river. It receives a mean annual rainfall of about 1,500 mm, concentrated during May-August with relatively little or no rains from November to February. The climate is temperate with mean temperature ranging from $12{ }^{\circ} \mathrm{C}$ to $25{ }^{\circ} \mathrm{C}$ during summer and from $-5{ }^{\circ} \mathrm{C}$ to $12{ }^{\circ} \mathrm{C}$ during winter, frost is common during winter. The cool summer weather makes the state a major tourist destination. The rocks of study area geologically belong to Hapoli formation and are considered to represent the lacustrine deposits in the inland basins [10].

\subsection{The Apatani Tribe}

The Apatani tribe belonging to the Tibeto-Mongoloid stock traces their decent from one legendary ancestor, the Abotani. Literally, the word 
Apatani is composed of two words: Apa (meaning display of affection) and Tani (meaning human race). Generally, they speak in their own local dialect that belongs to the Sino-Tibetan family which does not have any script. They are very superstitious and are nature worshippers. They mainly follow the Donyi-Polo, believing that the Donyi (the sun) and Polo (the moon) are the supreme gods that bless the community. The pattern of Apatani villages is that of string settlements, the indigenous village houses are in a straight line and are constructed mostly of bamboo (Phyllostachys bambusoides Siebold \& Zucc.) and pine (Pinus kesia, Pinus roxburghii, Pinus wallichiana and Pinus merkusii) timber. The traditional village council is regulated and administered by three local bodies namely, Akha Buliyang, Yapha Buliyang and Ajang Buliyang, comprising one or two people from each clan either based on heredity or by election.

The Apatani tribe of Arunachal Pradesh with a highly developed valley cultivation of rice perfected over centuries has often been suggested to be one of the relatively advanced tribal societies in the northeastern region of India [7]. Unlike other tribes who practice traditional slash-and-burn or shifting cultivation, majority of the ethnic Apatani has developed a unique agro-landscape management in the form of integrated rice + fish farming system, by virtue of which they distinguish themselves from other tribes of the state and define their distinctive lifestyle and social system. They have a distinct civilization with systematic land use practices and rich traditional ecological knowledge of natural resources management and conservation, acquired over the centuries through informal experimentation. This has made Ziro valley a good example of a living cultural landscape where man and environment have harmoniously existed together in a state of interdependence even through changing times, such co-existence being nurtured by the traditional customs and spiritual belief systems. Therefore, the Apatani plateau or Ziro valley has been tentatively listed by the United Nations Educational, Scientific and Cultural Organization (UNESCO) as one of the world heritage site due to its "extremely high productivity" and "unique" way of preserving the ecology [11].

\subsection{Household Survey}

A detailed survey was conducted using a structured questionnaire in seven villages (Bulla, Dutta, Hari, Hija, Hong, Bamin Michi and Mudang Tage) that were chosen randomly. Fifty households from each village were selected randomly to survey the traditional farming system and the objectives of the study were explained to the residents. The survey process involved extensive interviews and close consultation with household members, especially the older ones. The age of the respondents ( $70 \%$ male and $30 \%$ female) ranged from 25 years to 65 years. The interviews with farmers were conducted in their houses and/or on-farm sites. The group interviews, however, were conducted mainly during the mornings and evenings when most of the household members were available. The participatory approach, group discussions and interviews, allow the emergence of issue that force them to practice such type of productive farming system. The average size of a family is about eight, living in a large bamboo hut of $15 \times 4 \mathrm{~m}$ floor area. The tribe still maintains the age-old tradition for resources management and the modern scientific technology has little influence in this context. In contrast with the outlook of other tribes of the state who have been impacted by the wind of modernization and acculturation to a large extent, the Apartani tribe have strengthened the traditional systems of forest management, rice + fish farming, bamboo + pine plantation and land and water resource utilization.

\section{Description of the System}

\subsection{Rice Cultivation}

The Ziro valley was once believed to be having 
sporadic mountains, hills and marshy lands. It was the sincere and hardworking effort of their ancestors to make it suitable for wet rice cultivation. There are no written records, so, it is impossible to trace the exact history, date and time of origination of wet rice cultivation but through mythology, it is believed that it must have started at Pega-Sarang (name of place). Apatani oral literature, however, suggests that Hinkun Yari carrying rice crops from mythological place called Hinkun Lembyan met Ato Pussan and Ayo Tane at Miido Pyagan. There, she offered seeds of indigenous landraces of rice varieties to Ato Pussan and Ayo Tane for cultivation and till now, through several generations the crops are successfully cultivated.

The rice + fish farming practiced by the Apatani involves a uniquely ingenious way of water and agricultural resource management. Unlike the other rice + fish farming practices in the tropics [12-15], water for irrigating the fields is tapped from the streams originating from the nearby forests and adjacent catchment areas and diverted towards the agricultural fields, using traditional bamboo and pine-wood pipes. The water is usually diverted by a network of primary, secondary and tertiary channels. The water automatically flows down through the channels due to gentle slope and finally meets the major water channel at the lowest elevation which finally drains to the river Kele. The level of water is maintained by opening and closing inlets and outlets called hubur made of bamboo. The main canal may cause soil erosion in due course of time if proper care is not taken. For this, the bamboo fencing is made alongside main canals. Today one can even find concrete embankments constructed along the canals.

Maintaining this farming system is a tedious job because availability of sufficient water is critical for the growth and survival of fish without any negative impact on rice crops. The farming system is very lively based on a complex network of intricate irrigation canals and channels to ensure distribution of water in every corner involving peoples' participation. Equitable distribution of water in the fields is a general rule, such rules are regulated (enforced) by a few nominated members of the community, who are also empowered to resolve conflicts, if any. The members are also involved in harvesting the rainwater, building a network of canals for irrigating the rice fields and maintaining the system. The bunds (Agher), supported by bamboos and wooden clips are constructed in the fields in order to hold the water and retain the nutrient-rich soils. The average size of the bund is about $1 \mathrm{~m}$ in breadth and about $50 \mathrm{~cm}$ in height depending on the gradient of the land and shape and size of the fields.

\subsection{Field Preparation and Management}

The preparation for rice + fish farming starts just after the final harvest of rice in November (Fig. 2). The straw is left on the field to decompose while the chaff and spikes after separation of grains are taken to and spread in the field and allowed to dry, and are then burned. Other land preparation operations during December-January include installing inlets and outlets with bamboo pipes, raising and widening of bunds, and loosening and leveling the soil. For these operations, the farmers do not make use of animal power or, machines, nor do they use advanced tools to plow their fields. Instead, they prepare the fields with conventional daos (an implement for cutting) and spades - the farmers consider these practices economically and ecologically viable. The farmers rate weeds (Ahru-tamii) as a major problem. Generally, weeding (Ahru-hodo) starts in February which is manually done about three times per season with the help of traditional bamboo hoes where both man and women actively participate, forming groups called Patang. The uprooted weeds are left in the fields to decompose and sometimes weeds are converted into compost through traditional systems by gathering all the weeds in one place, which is then covered with a thin layer of soil for quick 


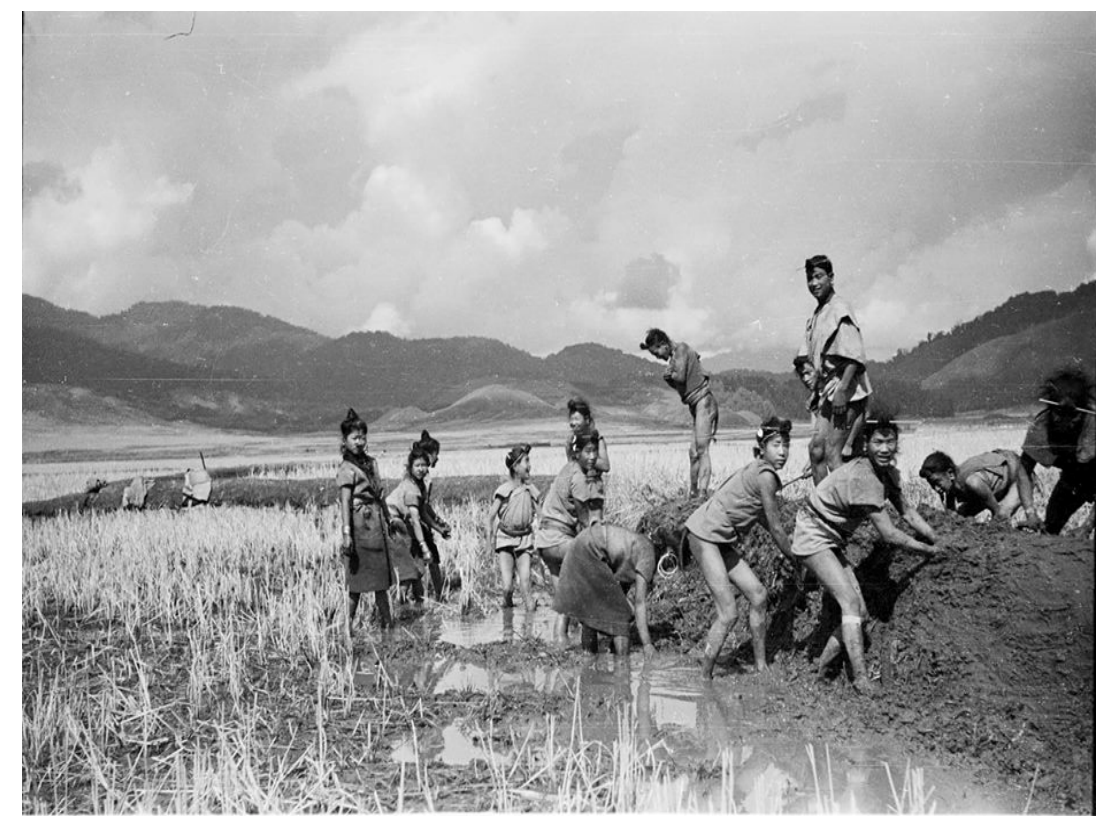

Fig. 2 The rural Apatani farmers of Ziro valley, Arunachal Pradesh, India preparing their agricultural land for cultivation.

decomposition [11]. The weeds collected in February from bunds are used as compost for rain-fed garden, mainly for cultivation of chilies (Capsicum spp.). Certain species such as Houttuynia cordata Thunb is considered as a good soil binder and is used for stabilizing bunds and are left behind in the field while weeding. Some weeds are consumed by fish so that weeding operations in the integrated rice + fish farming can be less frequent than in other agricultural systems where weeding is done three to five times during a cropping season.

The rice seedlings are first raised in the nursery (Miding) of about $48 \mathrm{~m}^{2}$, which is further divided into three to four nursery beds (Hohe) of $4 \times 3 \mathrm{~m}$ size [11]. Each indigenous landrace of rice (Table 1) is maintained separately to prevent possible mixed up of seedlings. The nursery beds are prepared just after the completion of murung festival in the month of February with the help of traditional implement (Hiita). The seeds are sown at the rate of about 80 $\mathrm{kg} \cdot \mathrm{ha}^{-1}$. The seedlings (Andee) are maintained with constant care for about 75 days until they attain the height of about $15 \mathrm{~cm}$ for transplanting. Interestingly, the seedlings of finger millet (Eleusine coracana (Linn.) Gaertn.), to be planted in the field bunds are generally raised in nursery beds in the homegarden. Rice along with four local varieties of finger millet are planted on elevated partitioned bunds between the rice plots (Figs. 3 and 4). The size, time and preparation technique of nursery beds are almost similar to those of rice. When the finger millet seedlings are about 15 $\mathrm{cm}$ tall, they are transplanted with the help of traditional implements (locally called Dum), after transplanting of rice seedlings from the nursery bed that begins in April is completed by the end of May.

\subsection{System Evaluation}

The average yields of rice and fish reported during the present study was about $3,700 \mathrm{~kg} \cdot \mathrm{ha}^{-1}$ rice and about $550 \mathrm{~kg} \cdot \mathrm{ha}^{-1}$ fish. Baruah et al. [16] reported production of about $2,300 \mathrm{~kg} \cdot \mathrm{ha}^{-1}$ rice and about 450 $\mathrm{kg} \cdot \mathrm{ha}^{-1}$ fish in neighboring state of Assam, India. Baruah et al. [17] also evaluated the prospects for fish farming in rice fields in Assam, and reported potential production of $500 \mathrm{~kg} \cdot \mathrm{ha}^{-1}$ rice in four months with a $17.7 \%$ increase in rice production, with $10-20$ percent of the plot utilized for dykes, refuge ponds and ditches. It has been reported that introduction of fish in rice fields increases rice yields by about $8 \%-15 \%[14,18]$. The increase in rice yield could also be due to a 
Table 1 Different indigenous landraces of rice (Oryza sativa Linn.) and finger millet (Eleusine coracana Linn. Gaertn.) cultivated by the rural Apatani farmers in Ziro valley of Arunachal Pradesh, India.

\begin{tabular}{|c|c|}
\hline Indigenous landraces of rice & Cultivation and approximate duration of crop (in days) \\
\hline \multicolumn{2}{|l|}{ Early varieties } \\
\hline Ampu ahare & Most commonly cultivated, 210 days \\
\hline Tepe pyaying & Most commonly cultivated, 215 days \\
\hline Kogii pyate & Commonly cultivated, 215 days \\
\hline Mithu mipye & Commonly cultivated, 205 days \\
\hline Pyare mipye & Commonly cultivated, 180 days \\
\hline Eylang mipye & Rarely cultivated, 215 days \\
\hline Kogii paying & Rarely cultivated, 215 days \\
\hline Mishang mipye & Rarely cultivated, 215 days \\
\hline Pyapu paying & Rarely cultivated, 205 days \\
\hline Pyate pyapu & Rarely cultivated, 205 days \\
\hline Zeehe pyaping & Rarely cultivated, 215 days \\
\hline Zeehe pyate & Rarely cultivated, 215 days \\
\hline \multicolumn{2}{|l|}{ Late varieties } \\
\hline Eylang eamo & Most commonly cultivated, 240 days \\
\hline Ampu hatte & Commonly cultivated, 250 days \\
\hline Radhe eamo & Rarely cultivated, 245 days. \\
\hline Ampu Puloo Hatte* & 270 days (no more cultivated) \\
\hline \multicolumn{2}{|l|}{ Millet varieties } \\
\hline \multicolumn{2}{|l|}{ Early variety } \\
\hline Surpu Ahare & Commonly cultivated, 175 days \\
\hline \multicolumn{2}{|l|}{ Late varieties } \\
\hline Surpu latha & Most commonly cultivated, 195 days \\
\hline Ahki sarse & Rarely cultivated, 190 days \\
\hline Sartii & Rarely cultivated, 190 days \\
\hline
\end{tabular}

* Now become extinct due to lesser use of the species.

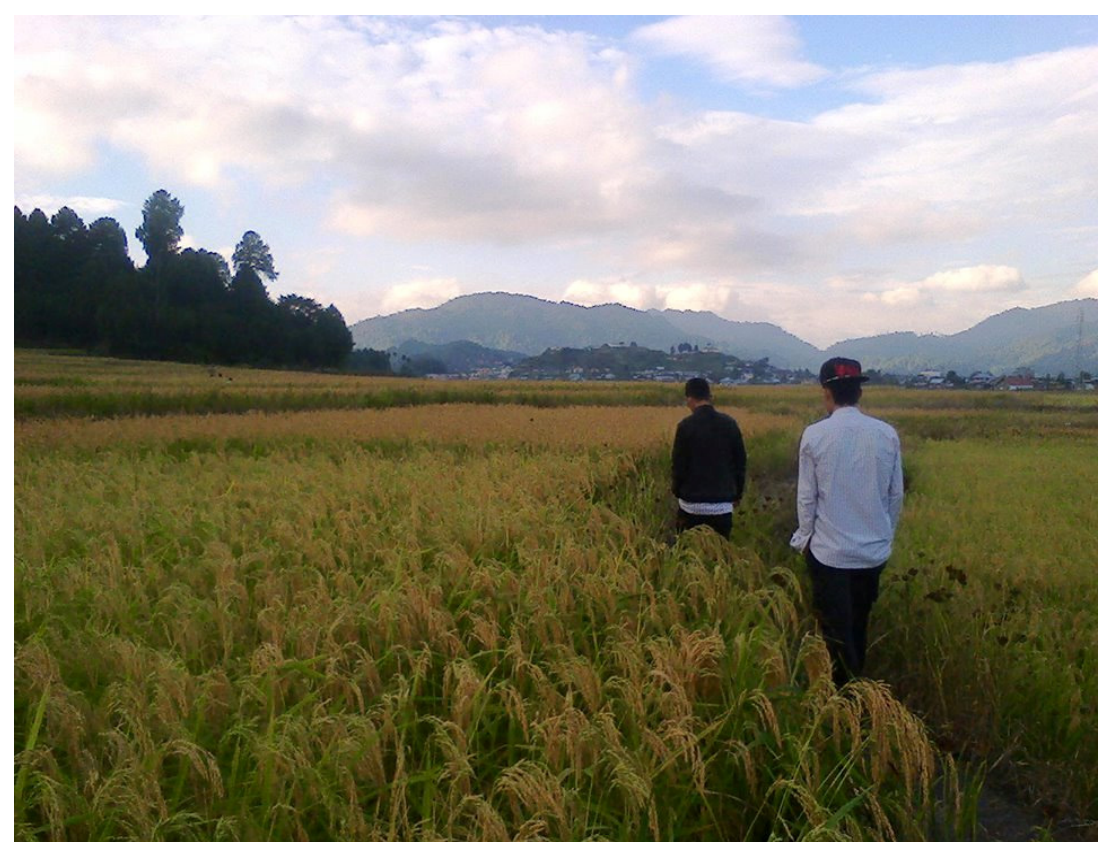

Fig. 3 Ripened indigenous landrace of rice (Oryza sativa Linn.) in Ziro valley of Arunachal Pradesh, India, where the local farmers practice ingenious rice + fish cultivation. 


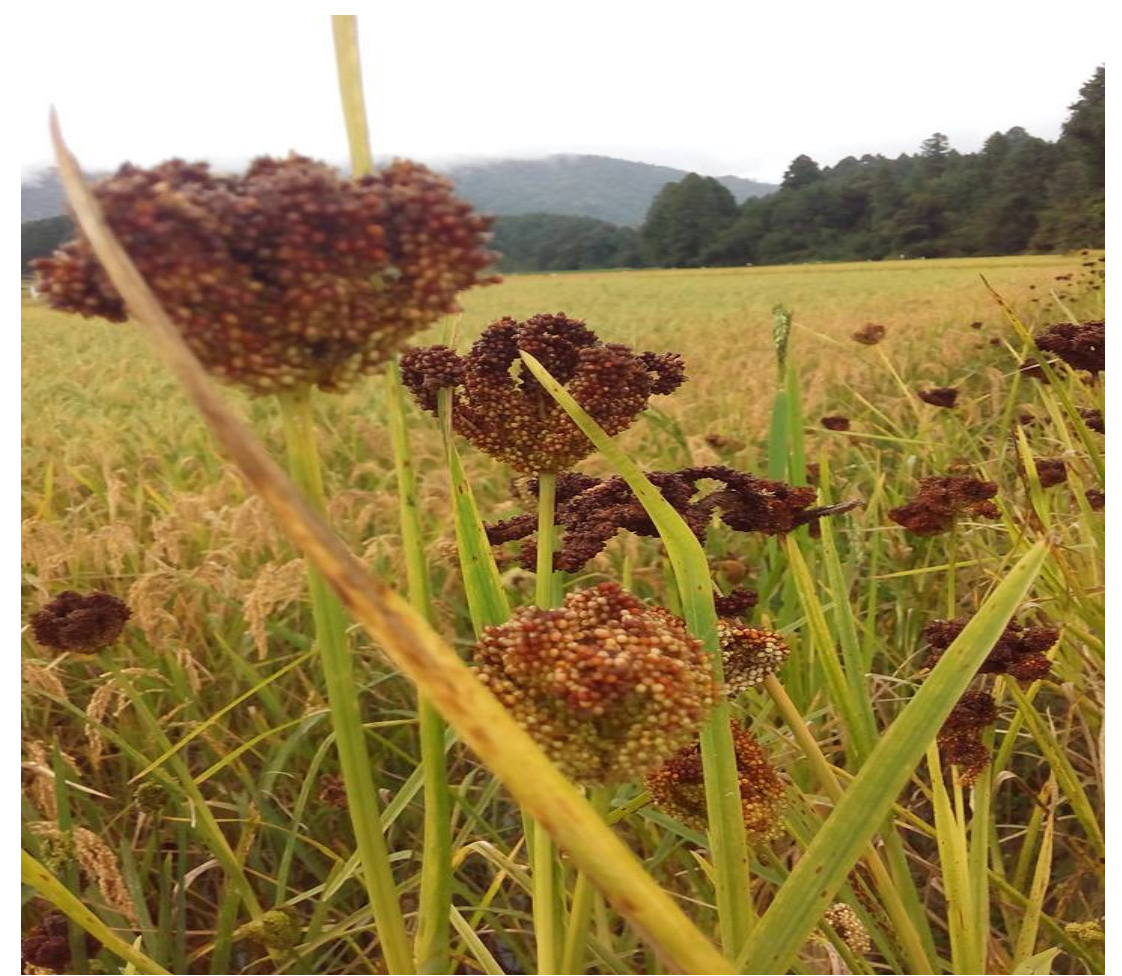

Fig. 4 Ripened indigenous millets (Eleusine coracana Linn. Gaertn.) cultivated in the elevated bunds between the rice plots by the Apatani tribe in Ziro valley of Arunachal Pradesh, India.

Table 2 Reported for yields of rice and fish under rice + fish culture of different studies $[12,16,19,20]$.

\begin{tabular}{lll}
\hline & Approximate yield $\left(\mathrm{kg} \cdot \mathrm{ha}^{-1}\right)$ & \\
\hline Rice grain & Fish (fresh weight) & Place/Country \\
\hline 3,700 & 550 & Arunachal Pradesh, India \\
$5,200($ Aman $)$ rice & 250 & Bangladesh \\
$4,900($ Boro $)$ rice & 250 & Bangladesh \\
3,890 & NA & Sri Lanka \\
2,580 & 530 & Nigeria \\
$2,100-2,300$ & $400-450$ & Assam, India \\
\hline
\end{tabular}

combination of several favorable factors associated with the movement of fish such as increasing dissolved oxygen levels, stirring up soil nutrients, enhancing soil organic matter, and controlling plankton, organic detritus, aquatic insects and plants that compete with rice for nutrients and energy [12]. The comparative data of few studies on yields of rice and fish in rice + fish farming system reported from different countries are presented in Table 2. There was a general belief among the local farmers that incorporation of fish with rice benefits rice cultivation due to better aeration of water and greater plowing from the movement of fish.
The fish fingerlings introduced by the Apatani farmers in the rice + fish fields are cyprinids such as common carp (Cyprinus carpio Linn.), grass carp (Ctenopharyngodon idella Val.), silver carp (Hypophthalmichthys molitrix Val.), rohu (Labeo rohita Ham.), Catla (Catla-catla Ham.) and Mrigal (Cirrhinus mrigala Linn.) in April and harvested in July (Fig. 5), during the cropping phase of the early rice. Gupta et al. [21] reported use of eight different fish species with paddy rice. The local farmers mentioned during the survey that about 2,500 fingerlings are usually used for one ha. Trenches, about $50 \mathrm{~cm}$ deep, are dug in the field to provide 


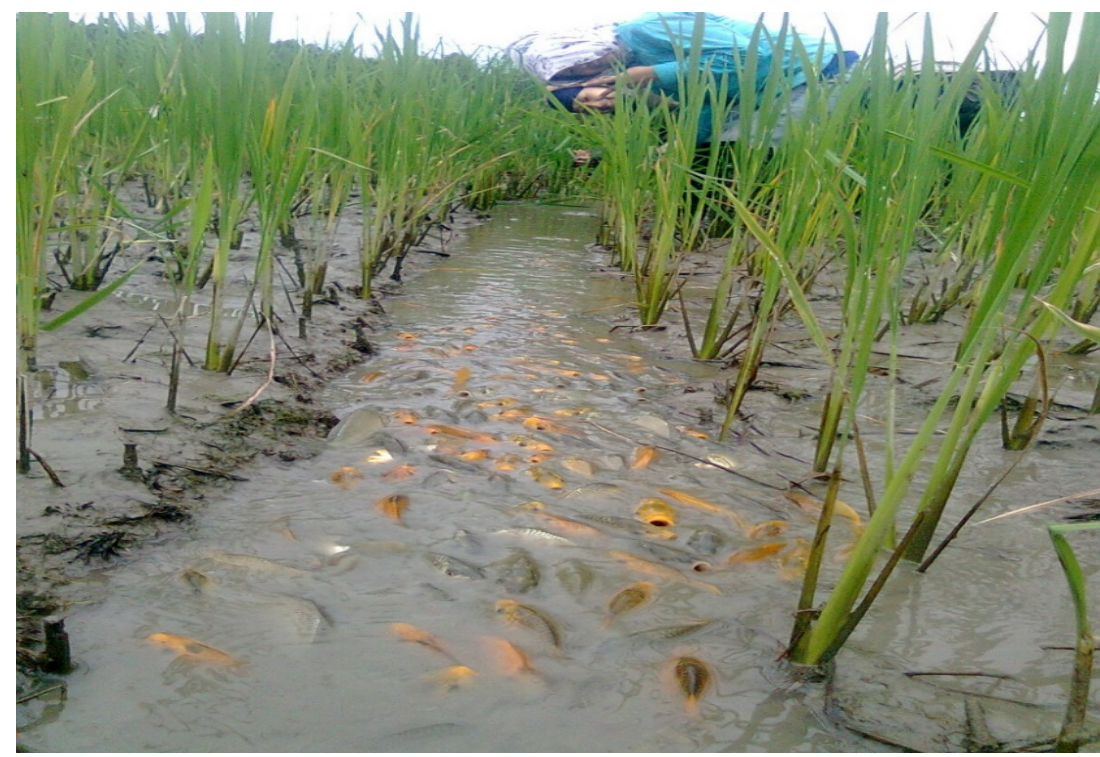

Fig. 5 Harvesting of fishes from integrated rice + fish farming in Ziro valley of Arunachal Pradesh, India.

shelter to fish. When water dries up in the field, fish takes shelter in these trenches where water still remains. During hot weather, the water in deep trenches provides soothing environment for the fish. Fishes are caught easily even during the harvest from the trenches using the indigenous trap prepared from bamboo which is placed in the outlets. About 80 percent of fish production in the valley comes from Cyprinus carpio followed by Ctenopharyngodon idella. Cyprinus carpio, an omnivore, stands out from other fish species because of its high viability. They can lay eggs under natural conditions in ponds or lakes, making it easy for farmers to collect them. If left unattended in the field, these eggs are even able to hatch out. This is the reason why Cyprinus carpio is the main fish species used in rice + fish systems [13].

The fish feeds primarily on natural food such as pteridophytic Azolla species, phytoplankton, zooplankton, periphyton, and benthos grown in the rice fields [22]. Presence of Azolla, a free-living, nitrogen-fixing species also adds to the nitrogen enrichment of soil. In China, Azolla is added to the rice + fish system, turning it into a rice + Azolla + fish system [23, 24]. The annual amount of nitrogen fixed by Azolla is estimated to be $243-402 \mathrm{~kg} \cdot \mathrm{ha}^{-1}$, making it the main source of nitrogen circulating in the system
[13]. The fish also feeds on small insects like water beetle, larvae, and others that are harmful to rice. Further, the fish feeds on flies, snails and insects, and can help to control malaria mosquitoes and water-borne diseases [25]. In turn, the waste materials of fishes work as manure to rice plants.

The rice + fish farming system has largely been practiced in a traditional way and has become an important agro-cultural activity of the Apatani tribe of Arunachal Pradesh. Indeed, the Apatani farmers do not have too many options other than practicing this ingenious farming system due to scarcity of arable land resources. As described by Altieri and Koohafkan and Altieri [26, 27], such farming systems are rooted in the ecological rationale of traditional small-scale agriculture representing long established examples of successful forms of community-based land-use systems. According to the local farmers' experience, the integrated rice + fish farming is considered sustainable, self-sufficient and efficient.

Rice is a globally important staple food crop. The rice + fish farming agro-landscape favor the conservation and maintenance of both indigenous rice and fish with a wide distribution and constituting diversified varieties. Kala et al. and Dollo et al. [11, 28] reported at least sixteen indigenous landraces of 
rice being cultivated by the Apatani tribe in Ziro valley, some details of these landraces are presented in Table 1. The choice of varieties, however, depends on the household preferences while the most preferred local rice varieties being cultivated are Ampu Ahare, Eylang Eamo and Ampu Hatte (because of their high productivity and socio-religious importance), which together cover about 70 percent of total wet rice fields. For conservation of traditional crop varieties, on-farm conservation in traditional agriculture systems has the advantage over other conservation methods because crop genetic diversity can be maintained as part of normal farm management [29, 30].

Overall, agriculture in Aruncahal Pradesh is mostly organic, with little or no use of synthetic fertilizers, pesticides, and other chemicals. Soil fertility in general is managed and maintained through recycling of agricultural wastes such as rice straw and husk, ash, weeds, cattle manure and domestic household wastes. The streams coming from the forest and flood the fields also carry many degraded organic products (decomposed litter) which may provide nutrient to the fields. As Altieri [31] has described, in many areas of the developing world, traditional farmers have developed and/or inherited complex farming systems, adapted to the local conditions that have helped them to sustainably manage harsh environments and to meet their subsistence needs, without depending on mechanization, chemical fertilizers, pesticides, or other technologies of modern agricultural science. The Apartani rice + fish system of Ziro valley is an excellent example of such indigenous, sustainable, organic agriculture, where the chemical-free nature of land management has led to holistic rural development. The tentative recognition of Ziro valley as a UNESCO world heritage center is a monumental recognition of the value of this traditional system and its desirable sociocultural and ecological attributes.

Rice + fish farming is conducive to the recovery of soil fertility and the prevention of soil degradation. The interview with the Apartani farmers revealed a facet of their traditional knowledge that the recycling of nutrients by the fish through feeding and depositing feces serve as both a natural fertilizer for rice and enrichment for soil. Zheng and Deng [32] reported that an experiment on integrated rice + fish cultivation for 3 years in the same plot showed an increase of $27.9 \%, 44.3 \%, 6.5 \%$ and $28.2 \%$ in soil total nitrogen, total phosphorus, total potassium and organic matter, respectively. According to $\mathrm{Lu}$ and $\mathrm{Li}$ [13], a total of $10 \%-20 \%$ of methane $\left(\mathrm{CH}_{4}\right)$ in the atmosphere comes from rice fields and the rice + fish farming system is capable of lowering the emission of the $\mathrm{CH}_{4}$ by nearly $30 \%$ compared with traditional rice farming. Comparing $\mathrm{CH}_{4}$ emission rates from rice systems, Huang et al. [24] reported $4.73 \mathrm{mg} \cdot \mathrm{m}^{-2} \cdot \mathrm{ha}^{-1}$ from sole crop rice system as opposed to $1.71 \mathrm{mg} \cdot \mathrm{m}^{-2} \cdot \mathrm{ha}^{-1}$ fromrice + fish system.

\subsection{Mutualistic Association}

This ingenious farming system is one of the best examples of mutualism of biotic interactions, where both rice and fish are benefited. The principle of symbiosis and mutual-benefits of ecosystems, and the principle of the food web are applied to optimize the current ecosystem comprising fish, rice and aquatic microbes, so that each subsystem takes advantage of and promotes one another. In this relation, fish has the advantage for shelter and feeding, while rice has the privilege for luxurious nutrient uptake, and competitive advantages over weeds and micro flora (minute algae). Fish play a significant role in controlling aquatic weeds and algae that carry diseases, act as hosts for pests that would have compete with rice for nutrients. Shading by rice plants also maintains the water temperature favorable to fish during summer [33]. The decaying leaves of rice offer favorable conditions for the multiplication of microorganisms, which are the main fish feed. Fish, on the other hand, help to loosen the surface soil on which rice is planted, bringing about increased permeability and oxygen content of the soil, as well as 
enhanced vitality of microbes. Thus, the decomposition of nutrients in the soil is quickened, making it easy for rice to absorb. This cumulatively results in funneling of energy and matter of rice field ecosystem towards fish and rice production to benefit the farmers [34]. Integrated rice + fish farming is also being regarded as an important element of integrated pest management as the fish consume some of the weeds and pests leading to higher yield of rice [35, 36]. As reported by $\mathrm{Lu}$ and $\mathrm{Li}$ [13], fish can prey on the rice leaf hopper, Naranga aenescens Moore, and on Parnara guttata Bremer Grey on the water surface, especially omnivorous fish such as Tilapia nilotica and Cyprinus carpio. As a result, the application of pesticides in rice + fish systems is substantially reduced to almost none than that of modern, high-input rice production. In this way, both fish and rice are positioned in a sound ecological environment with positive circulation systems, strengthened integrated functions and enhanced production abilities [37].

Thus, this multi-dimensional ingenious rice + fish farming is a viable, environmental friendly, economically attractive, and low-cost, low-risk activity with multiple benefits including increased income and availability of fish for domestic consumption [38-40], system biodiversity, and decreased use of fertilizers and pesticides [12, 15]. This indigenous farming technology can play a crucial role in food security, income, nutrition [38, 41] and livelihood of the rural folk. Fish, particularly small fishes, are rich in micronutrients and vitamins, and thus human nutrition can be greatly improved through fish consumption [42]. Apart from use by individual households, the rice and fishes when in surplus are also sold to raise cash income.

\section{Conclusions}

The ingenious integrated rice + fish farming system of the Apatani is in urgent need of dynamic conservation. The traditional conservational attitude of local farmers to managing the rich natural resources helps them reap economic self-sufficiency and ecosystem services in this ecologically-fragile Arunachal Himalaya, northeastern India. This indigenous farming system provides an excellent example of integration of traditional ecological knowledge with scientific and eco-friendly techniques of conservation practices that help accomplish a systematic approach to resource management with economic viability. Exploitation of rice + fish farming system will not only provide an opportunity for people to learn about agriculture and ecology of this particular tribe but will enormously enhances its ecotourism potential, so that the income of the subsistence rural folks are enhanced and this important, indigenous agro-landscape is conserved and developed. A number of significant challenges, however, exist for the adoption of integrated rice + fish farming, particularly the lack of technical knowledge of farmers, and risks associated with flood and drought. Hence, proper training should be imparted that would help enriching the knowledge of rural farmers' improving productivity and reducing risks. A full recognition of its multi-ecological functions must be achieved, such as its role in preserving biological diversity, protecting food security, enriching soil and lowering the emission of greenhouse gases.

\section{Acknowledgements}

The authors would like to extend their gratitude to the farmers of Ziro valley for their invaluable contributions throughout the survey. Financial assistance from the Department of Biotechnology, New Delhi, Government of India, to the first author is highly appreciated.

\section{References}

[1] Cairns, M. 2015. Shifting Cultivation and Environmental Change: Indigenous People, Agriculture and Forest Conservation. New York: Taylor and Francis.

[2] Cairns, M. 2007. Voices from the Forest: Integrating 
Indigenous Knowledge into Sustainable Farming. Washington, DC: Resources for the Future.

[3] Power, A. G. 2010. "Ecosystem Services and Agriculture: Tradeoffs and Synergies." Philosophical Transactions of the Royal Society B 365: 2959-2971. doi:10.1098/rstb.2010.0143.

[4] Pretty, J., Morrison, J. I. L., and Hine, R. E. 2003. "Reducing Food Poverty by Increasing Agricultural Sustainability in Developing Countries." Agriculture, Ecosystems and Environment 95: 217-34.

[5] Altieri, M. A. 2009. "Agroecology, Small Farms, and Food Sovereignty." Monthly Review 61: 102-111. doi:10.14452/MR-061-03-2009-07_8.

[6] Denevan, W. M. 1995. "Prehistoric Agricultural Methods as Models for Sustainability." Advanced Plant Pathology 11: 21-43.

[7] Furer-Haimendorf, C. V. F. 1962. The Apatanis and Their Neighbors: A Primitive Civilization of the Eastern Himalaya. London: Routledge \& Kegan Paul Ltd..

[8] Arunachal Pradesh Profile-Census of India. 2011. "Our Census, Our future.” Accessed November 26, 2015. http://censusindia.gov.in.

[9] Kumar, A., and Ramakrishnan, P. S. 1990. "Energy Flow through an Apatani Village Ecosystem of Arunachal Pradesh in North-East India." Human Ecology 18: 315-336.

[10] Tangjang, S., and Arunachalam, A. 2009. "Role of Traditional Homegarden Systems in Northeast India." Indian Journal of Traditional System 8: 47-50.

[11] Dollo, M., Samal, P. K., Sundriyal, R. C., and Kumar, K. 2009. "Environmentally Sustainable Traditional Natural Resource Management and Conservation in Ziro Valley, Arunachal Himalaya, India." Journal of American Science 5: 41-52.

[12] Ahmed, N., and Garnett, S. T. 2011. "Integrated Rice-Fish Farming in Bangladesh: Meeting the Challenges of Food Security." Food Sec. 3: 81-92. doi:10.1007/s12571-011-0113-8.

[13] Lu, J., and Li, X. 2006. "Review of Rice-Fish-Farming Systems in China-One of the Globally Important Ingenious Agricultural Heritage Systems (GIAHS)." Aquaculture 260: 106-113.

[14] Mishra, A., and Mohanty, R. K. 2004. "Productivity Enhancement through Rice-Fish Farming Using a Two-Stage Rainwater Conservation Technique." Agricultural Water Management 67: 119-131.

[15] Rothuis, A. J., Nhan, D. K., Richter, C. J. J., and Ollevier, F. 1998. "Rice with Fish Culture in the Semi-deep Waters of the Mekong Delta, Vietnam: A Socio-Economical Survey." Aquaculture Research 29: 47-57.

[16] Baruah, U. K., Talukdar, R. K., Goswami, U. C., and Bhagowati, A. K. 1999. "Impact of Evaluation of
Community Management of Rice Field System in Assam, India." Indian Journal of Fisheries 46: 205-209.

[17] Baruah, U. K., Bhagowati, A. K., and Talukdar, R. K. 2000. "Prospects of Fish Farming in Rice Fields in Assam.” Indian Journal of Fisheries 47: 149-159.

[18] Mohanty, R. K., Verma, H. N., and Brahmanand, P. S. 2004. "Performance Evaluation of Rice-Fish Integration System in Rainfed Medium and Ecosystem." Aquaculture 23: 125-135.

[19] Jayaweera, B. P. A., Edirisinghe, U., and Ranaweera, B. 2007. "Integration of Goldfish (Carassius auratus) Culture with Organic Rice Farming." Tropical Agricultural Research 19: 290-300.

[20] Dirisu, S. O., Muinat, B., and Yakubu, D. M. 2007. "Polyculture and Fish Yield in Rice-Cum-Fish Culture System in Dadin Kowa, Gombe, Nigeria." Animal Research International 4: 737-740.

[21] Gupta, M. V., Sollows, J. D., Mazid, M. A., Rahman, A., Hussain, G., and Dey, M. M. 1998. Integrating Aquaculture with Rice Farming in Bangladesh: Feasibility and Economic Viability, Its Adoption and Impact. Manila, Philippines: ICLARM (International Center for Living Aquatic Resources Management).

[22] Mustow, S. E. 2002. "The Effects of Shading on Phytoplankton Photosynthesis in Rice-Fish Fields in Bangladesh." Agriculture, Ecosystems and Environment 90: 89-96.

[23] Huang, Yibin, Wen, Boqi, Tang, Jianyang, Liu, and Zhongzhu. 2001. "Effect of Rice-Azolla-Fish System on Soil Environment of Rice Field." Chinese Journal of Eco-agriculture 9: 74-76.

[24] Lin, Z. 1996. "Technology and Benefits of Controlled Paddy Field." Journal of Soil and Fertilizer 4: 37-41.

[25] Matteson, P. C. 2000. "Insect-Pest Management in Tropical Asian Irrigated Rice Fields.” Annual Review Entomology 5: 549-574.

[26] Altieri, M. A. 2004. "Linking Ecologists and Traditional Farmers in the Search for Sustainable Agriculture." Frontiers in Ecology and the Environment 2: 35-42.

[27] Koohafkan, P., and Altieri, M. A. 2010. Globally Important Agricultural Heritage Systems: A Legacy for the Future. Rome: UN-FAO.

[28] Kala, C. P., Dollo, M., Farooquee, N. A., and Choudhury, D. C. 2008. "Land-Use Management and Wet-Rice Cultivation (Jebi Aji) by the Apatani People in Arunachal Pradesh, India." Outlook on Agriculture 37: 125-129.

[29] Barry, M. B., Pham, J. L., Courtois, B., Billot, C., and Ahmadi, N. 2007. "Rice Genetic Diversity at Farm and Village Levels and Genetic Structure of Local Varieties Reveal Need for in Situ Conservation." Genetic Resources and Crop Evolution 54: 1675-1690.

[30] Kumar, S., Bisht, I. S., and Bhat, K. V. 2010. "Population 

Subsistence in Arunachal Pradesh, India

Structure of Rice (Oryza sativa) Landraces under Farmer Management." Annals of Applied Biology 156: 137-146.

[31] Altieri, M. A. 2002. "Agroecology: The Science of Natural Resource Management for Poor Farmers in Marginal Environments." Agriculture, Ecosystem and Environment 93: 1-24.

[32] Zheng, Y., and Deng, G. 1998. "Benefits Analysis and Comprehensive Evaluation of Rice-Fish-Duck Symbiotic Model." Chinese Journal of Eco-Agriculture 6: 48-51.

[33] Kunda, M., Azim, M. E., Wahab, M. A., Dewan, S., Roos, N., and Thilsted, S. H. 2008. "Potential of Mixed Culture of Freshwater Prawn (Macrobrachium rosenbergii) and Self-Recruiting Small Species Mola (Amblypharyngodon mola) in Rotational Rice-Fish/Prawn Culture Systems in Bangladesh." Aquaculture Research 39: 506-517.

[34] Gurung, T. B., and Wagle, S. K. 2005. "Revisiting Underlying Ecological Principles of Rice-Fish Integrated Farming for Environmental, Economical and Social Benefits." Our Nature 3: 1-12.

[35] Berg, H. 2001. "Pesticide Use in Rice and Rice-Fish Farms in the Mekong Delta, Vietnam." Crop Protection 20: 897-905.

[36] Halwart, M., and Gupta, M. V. 2004. Culture of Fish in Rice Fields. Penang, Malaysia: Food and Agriculture Organization of the United Nations, and the World Fish
Center.

[37] Wu, L. 1995. "Methods of Rice-Fish Culture and Their Ecological Efficiency." In Rice-Fish Culture in China, edited by MacKay K. T. Ottawa: IDRC.

[38] Desta, L., Prabha, D. L., Sreenivasa, V., and Amede, T. 2014. "Studies on the Ecology of the Paddy and Fish Co-culture System at Dembi Gobu Microwater Shed at Bako, Ethiopia." International Journal of Fisheries and Aquatic Studies 1: 49-53.

[39] Goswami, M., Biradar, R. S., and Sathiadhas, R. 2004. "Techno-Economic Viability of Rice-Fish Culture in Assam." Aquaculture Economics \& Management 8: 309-317.

[40] Saikia, S. K., and Das, D. N. 2008. "Rice-Fish Culture and Its Potential in Rural Development: A Lesson from Apatani Farmers, Arunachal Pradesh, India." Agriculture and Rural Development 6: 125-131.

[41] Noorhosseini-Niyaki, S. A., and Allahyari, M. S. 2012. "A Logistic Regression Analysis: Agro-technical Factors Impressible from Fish Farming in Rice Fields, North of Iran." International Journal of Agricultural Management \& Development (IJAMAD) 2: 223-227.

[42] Roos, N., Islam, M. M., and Thilsted, S. H. 2003. "Small Indigenous Fish Species in Bangladesh: Contribution to Vitamin A, Calcium and Iron Intakes." Journal of Nutrition 133: 4021S-4026S. 